\title{
La figura de la pérdida como catástrofe del individuo contemporáneo en la trilogía $U n$ animal mudo levanta la vista de Germán Marín: Una lectura desde Peter Sloterdijk
}

The figure of loss as catastrophe of the contemporary individual in the trilogy Un animal mudo levanta la vista by

Germán Marín: A reading based on Peter Sloterdijk

\section{AndRea KotTow}

Universidad Andrés Bello. Santiago, Chile.

akottow@yahoo.com

\section{RESUMEN}

El artículo realiza una lectura de las novelas El palacio de la risa, Ídola y Cartago de Germán Marín desde la imagen de la pérdida del individuo de un cobije unitario, simbólicamente representado por la burbuja diádica propuesta por el filósofo Peter Sloterdijk. Se muestra a partir de un diálogo entre Marín y Sloterdijk que la narrativa del escritor chileno reitera en su trama la catástrofe de una pérdida irrecuperable del individuo moderno, quedando expulsado de una esfera protectora trascendente. La historia reciente de Chile se evidencia como metonimia de un cataclismo existencial, propio de un ser humano entendido desde la falta.

Palabras claves: Burbuja diádica, catástrofe existencial, dictadura chilena.

\section{ABSTRACT}

The article suggests a reading of the novels El palacio de la risa, Ídola and Cartago by 
Germán Marín, departing from the image of the individual's loss of a uniting shelter, symbolically represented by the dyadic bubble proposed by the philosopher Peter Sloterdijk. Putting into dialogue Marín and Sloterdijk, this article shows that the narrative of the Chilean writer reiterates in its plot the modern individual's catastrophe of an irretrievable loss, remaining expelled of a significant protective sphere. The recent history of Chile functions as a metonymy of an existential cataclysm of the human being understood as marked by a lack.

Keywords: Dyadic bubble, existential catastrophe, chilean dictatorship.

Recibido: 14-09-2010. Aceptado: 24-10-2010.

[...] Oder daß ein Tier, ein stummes, aufschaut, rubig durch uns durch.

Dieses heißt Schicksal: gegenüber sein und nichts als das und immer gegenüber' .

Rainer Maria Rilke

\section{A MODO DE INTRODUCCIÓN: EL ANIMAL MUDO DEL DESTINO}

- $\mathrm{n}$ la octava de sus Elegias de Duino, Rainer Maria Rilke reflexiona poéEticamente sobre el destino del ser humano, simbolizado como aquel animal mudo cuya mirada atraviesa al hombre que tiene enfrente, sin posibilidad de esquivarlo ni de interpelarlo. En esta configuración poética, el ser humano está eternamente despidiéndose, marcado por una falencia, una pérdida que no podrá volver a enmendar más. Se despide porque lleva las huellas indelebles de aquello que ha perdido, no pudiendo llenar el vacío de lo que ya no posee, pudiendo tan sólo enfrentarse a este destino ineluctable.

Compuesta por las novelas El palacio de la risa (1995), Ídola (2000) y Cartago (2002), Germán Marín reúne los tres textos en la trilogía Un animal mudo levanta la vista (2002). Resuena aquel verso del melancólico poeta alemán, en el cual este animal mudo, que es el destino, levanta la vista para

\footnotetext{
${ }^{1} \mathrm{O}$ que un animal, uno mudo, tranquilo mira y ve a través nuestro. Esto se llama "destino": el estar-de-frente-a y nada si no es eso y el siempre de-frente-a. Trad. de Eustasio Barjau.
} 
atravesarnos con una mirada que no permite posibilidad de comunicación, abandonándonos a una obligada actitud de pasividad doliente. La trilogía de Marín propone a su vez una mirada sobre la historia reciente de Chile, reseñada como aquel destino ineludible y catastrófico que no permite vuelta atrás ni olvido, marcando al individuo como protagonista de una pérdida no sólo contingente sino también existencial.

Como en todas las novelas que hasta ahora publicara Germán Marín, el juego de la verosimilitud, que plantea un lazo peculiar entre realidad y ficción, se erige como la propuesta de un pacto de lectura a sus lectores: el narrador-personaje en primera persona de las tres novelas es un "proyecto de escritor", también denominado "ex-escritor", ya entrado en años, de nombre Germán, cuyas coordenadas biográficas básicas coinciden con las de su creador. Germán vuelve tras largos años de exilio político a Chile, encontrándose tanto con los fantasmas del pasado que lo llevaron a abandonar Chile en la época de la dictadura, como también con un país cuya actual lógica de funcionamiento le es tan extraña como hostil. En las tres novelas se cuenta la historia de una reiterada catástrofe, que nos habla de ese destino que, simbolizado en la rilkiana figura del animal mudo, se constituye como experiencia existencial del individuo. Un individuo que en las novelas de Marín busca la reconexión con un "algo" perdido, una unidad que le posibilite experimentar un sentido elusivo de plenitud, que siempre se evidencia como ilusorio o tan sólo momentáneo.

La presente aproximación a la trilogía de Germán Marín propone leer las novelas constituyentes de Un animal mudo que levanta la vista desde el modelo de la pérdida de una vinculación dual, disipada experiencia que para el personaje central de los textos se erige como catástrofe existencial, que termina por dejarlo abandonado en el desastre de la desolación. Las tres novelas comparten un arco de trama similar, el cual se estructura en torno a la vana posibilidad de recrear un vínculo que pudiese colmar el vacío existencial del personaje. Sin embargo, lo que sugiere la opción de llenar el hueco termina por abrirlo aun más y señala al personaje como un ser en falta.

La lectura que domina la bibliografía crítica acerca de Marín está marcada por un anclaje en lo biográfico e histórico. Germán Marín aparece en estas aproximaciones en tanto crítico del Chile actual, denunciando un neoliberalismo que ha vuelto irreconocible un antaño lugar de pertenencia. El análisis de la novela Ídola de Iván Barreto (2006) es paradigmático para esta recepción. Germán es aquí el personaje que experimenta las consecuencias del neoliberalismo instalado en Chile por la dictadura militar, viviendo el fracaso de la cultura letrada. Barreto recoge en su artículo la discusión que 
en torno a la "lumpenización" (Espinosa, 2000 y Cuevas, 2001) -en tanto proceso socio-económico consecuente del sistema neoliberal impuesto por la dictadura- que se hubiera producido en Chile. Espinosa "acusa" a Ídola en tanto novela que ridiculizaría la clase y cultura popular, mostrándose en este rechazo el racismo de la intelectualidad y el sentimiento de superioridad de la figura del letrado. José Ángel Cuevas sostiene que la lumpenización traería como consecuencia la barbarización de la ciudad, proceso plasmado en la novelística de Marín. Barreto sigue más bien esta segunda línea interpretativa, viendo que la lumpenización abarca toda la novela y sus personajes, evidenciándose las consecuencias del sistema neoliberal: "Este proceso determina finalmente el olvido de la procedencia y la imposibilidad de encontrar [...un] origen buscado". Asimismo Costabal (2008) refiere la "amnesia" reinante en el Chile contemporáneo con relación a su historia reciente en su aproximación a la novela El palacio de la risa.

Lo que estas propuestas de lectura comparten es la vinculación que establecen entre la novelística de Marín y la contingencia chilena. Sin estar en desacuerdo con este modo interpretativo y retomando elementos importantes de él, el siguiente trabajo pretende ampliar la mirada sobre la obra de Marín leyéndola más allá de los elementos que de manera verosímil se enlazan con la historia chilena de la dictadura y la transición. Las siguientes páginas sostienen que la pérdida de un modo armónico de relacionarse con el entorno no sólo da cuenta de una interpretación crítica de la historia chilena actual, sino que ésta sirve para actualizar y simbolizar una catástrofe existencial a partir de la cual el ser humano pierde la posibilidad de cohabitar con otros en un espacio unitario que le confiera un cobijo trascendental.

\section{BURBUJAS DIÁDICAS}

Para esta lectura haremos dialogar los textos de Marín con el primer tomo, Burbujas, de Esferas del filósofo alemán Peter Sloterdijk. Los tres tomos, que en su conjunto componen su "Esferología", están organizados en torno a la premisa de considerar la vida como un asunto formal, convirtiendo su proyecto escritural-filosófico en una teoría espacial. Vivir, constituir esferas y pensar serían expresiones distintas para una y la misma actividad. Cualquier historia de amor como, de manera más general, cualquier acto de solidarización serían intentos de construir esferas, de crear espacios interiores e íntimos cuya finalidad consistiría en proteger frente a las amenazas múltiples del mundo exterior. Lo que definiría entonces la esfera es "[...] 
eine zweihälftige, von Anfang an polarisierte und differenzierte, gleichwohl innig verfugte, subjektive und erlebende Kugel -ein zwei-einig gemeinsamer Erlebnis- und Erfahrungsraum" (45) ${ }^{2}$.

El sujeto moderno, heredero del cartesianismo, es uno que pone en juego la protección conferida por la burbuja diádica, vulnerando sus sistemas inmunológicos al insistir en su individualidad y en la expulsión del otro polo componente de un espacio esferológico compartido. La modernidad se caracterizaría por producir técnicamente su inmunidad y por extraer sus estructuras protectoras cada vez más de relatos tradicionales teológicos y/o cosmológicos, renunciando de este modo a la esfera, celebrando su desprendimiento, pero no pudiendo enmendar del todo la nostalgia de algo perdido. Sloterdijk pretende demostrar que el Ser-en-esferas es la relación primaria del ser humano, siendo las esferas construcciones morfo-inmunológicas, desarrolladas en el entorno para la protección de las subjetividades. Tanto en la imagen fundacional mítica de Jahwe y Adán, en la terminología psicoanalítica de la díada madre-hijo, como también en las figuras poéticas/ existenciales de los amantes inseparables, de los mellizos, de la alianza indestructible de dos aparecen ligazones esféricas, en las que sólo una radical resonancia entre ambos polos le confiere su mutua vitalidad y espiritualidad.

Las esferas son, no obstante, construcciones frágiles y están amenazadas por una inestabilidad constitutiva que pone constantemente en peligro su inmunidad; traen consigo el germen de su propia destrucción. La parábola bíblica de la expulsión del paraíso es el paradigma mítico de la catástrofe originaria del ser humano, consistente en la destrucción irremediable de su protección esferológica. Sloterdijk sitúa en este momento de pérdida inicial el nacimiento de la psiquis humana; el surgimiento de un principio vital puntual que funciona simultáneamente como chispa individualizante es pensado como el resultado de la corrupción de la unidad dual originaria. La burbuja, en tanto esfera vulnerable, está así siempre deviniendo hacia su estallido. Hablar sobre esferas implica simultáneamente hablar de su destrucción.

Sloterdijk inicia sus Esferas I con la imagen del niño que sopla pompas de jabón, siguiendo con la mirada la frágil constitución esférica que ha, literalmente, desembocado de su expiración; la fascinación del niño es doble:

\footnotetext{
${ }^{2}$ En el texto las citas de Sloterdijk se mantienen en su original alemán, ofreciéndose las traducciones respectivas en las notas finales. Todas las traducciones pertenecen a la edición de Siruela, hechas por Isidoro Reguera. "Lo que aquí se llama esfera sería, por consiguiente, en una comprensión primera y provisional, un globo de dos mitades, polarizado y diferenciado desde el comienzo, ordenado interiormente sin embargo, subjetivo y capaz de sensibilidad: un espacio común de vivencia y de experiencia, dúplice y único a la vez" (51).
} 
se siente creador de aquello que flota por los aires pero espera asimismo con anhelante temor que la burbuja se rompa, destruyendo de este modo también una parte de sí mismo en tanto autor de su creación. La burbuja, espacio siempre dual, conformado por dos elementos fundidos en uno solo, está destinada a su propia destrucción, simbolizando así el drama originario del in-dividuo, de aquel que ha sido dividido.

La trilogía de Marín nos posiciona frente a la burbuja que se malogra, frente a ese niño que anhela la unidad de su creación, mas obligado a ver -fascinado y aterrorizado a la vez- cómo se destruye. En las tres novelas de Un animal mudo que levanta la vista el narrador-personaje busca la reconstitución de una unidad perdida, en la cual el sujeto forma parte de una entidad que lo trasciende que, a pesar de los esfuerzos, se devela como imposible. A continuación proponemos un recorrido por los tres textos para rastrear las coordenadas de esta historia catastrófica de la pérdida de una unidad cuya recuperación no puede dejar de ser intentada, a pesar de lo vano del esfuerzo. Sería justamente esta paradoja entre tres movimientos - pérdida, búsqueda fútil de restitución, irrecuperabilidad- la que configura el destino, coronado como animal mudo a partir del intertexto con el poeta Rilke.

\section{SUPERPOSICIÓN DE ESPACIOS Y TIEMPOS EN EL PALACIO DE LA RISA}

Una casona de mediados del siglo XIX en el barrio santiaguino de Peñalolén se encuentra en el centro de esta breve novela, primer tomo de la trilogía. La historia de la casa se remonta al siglo XIX, en el cual albergó lo más aristocrático e ilustre de la sociedad chilena. Una vez regresado del exilio, Germán busca en los parajes vacíos que ahora marcan el espacio donde antaño se encontraba la casona la recreación de la historia que lo vincula a este entorno, desde que la visitara en su infancia. Los recuerdos de los días pasados en este espacio se grabarán en la memoria de Germán:

La fragancia de aquellas tardes, mezcla de flores vivas y restos invernales, no se borraría de mí hasta el grado de que en Barcelona, durante el exilio, más de una vez desperté anhelante de madrugada, desorientado en la oscuridad, llamado en el sueño por esa evocación $(42)^{3}$. la vista.

${ }^{3}$ Todas las citas de las novelas de Marín están sacadas del tomo Un animal mudo que levanta 
Otro recuerdo del pasado estará asociado al palacio: ya como adulto, Germán vuelve a Peñalolén para constatar que la casa se ha convertido en una discoteca de nombre "El Paraíso". Es, en la propia percepción de Germán, el comienzo de la decadencia que se convertirá en la marca fatal de la casona que fuera en tiempos de dictadura la Villa Grimaldi.

La velada que Germán pasa en la discoteca junto a Mónica, una estudiante de inglés del Instituto Pedagógico que será su amante, se constituye en el origen de su idilio amoroso, interrumpido cuando Germán, tras el golpe militar de 1973, debe salir al exilio político. La noche de la visita en "El Paraíso", Germán vuelve a recorrer los pasillos y las piezas de la villa que conociera en su infancia. Los recuerdos se superponen con la calidez que le provoca la compañía de Mónica, y Germán se siente dolido frente a los cambios que ha sufrido un espacio que se colma de familiaridad en su memoria:

Mientras removía el cubo de hielo del trago, sentado en un taburete al lado de Mónica, no dejaba inconscientemente de hacer volver las cosas a su lugar, pues aunque la realidad fuese porfiada ante lo que me había mostrado esa noche, me resistía a aceptar el vuelco que había sufrido la finca de Peñalolén (60).

La socavación de los recuerdos espaciales implica a su vez un desfase temporal, que convierten el presente en un lugar imposible de habitar. Germán se siente expulsado de sus espacios y tiempos biográficos, su existencia mostrándose como un anhelo siempre negado de hacer coincidir los retazos espaciales y temporales que lo configuran en tanto personaje.

Aun más abismal y trágico es verse enfrentado a su vuelta del exilio al sitio eriazo que ahora se encuentra en lugar de la casa de Peñalolén, una borradura que intenta vanamente hacer desaparecer los horrores que la misma albergó en tiempos de dictadura. Esta desaparición de un espacio que había conformado para Germán un lugar de armónico ordenamiento de su infancia se corresponde con la sensación de pérdida que lo domina en relación con su retorno a Chile. Este sentimiento de encontrarse expulsado, sin pertenencia, es reiterado en la trilogía justamente a partir de la certeza de ser un extraño en todo lugar y en el tiempo presente. La certeza que adquiere acerca de la participación de Mónica como colaboradora del régimen militar, termina por sellar la imposible reconciliación que Germán intenta con su propia historia. Tal como el narrador-personaje pretende que el enfrentamiento con el paisaje de Peñalolén lo reconcilie con aquel lugar que tanto significara para 
él, desea que la reconstrucción de la vida y la "verdad" acerca de Mónica le puedan entregar claves para su desgarrada existencia. Así como a Germán se le hace imposible entender cómo el tradicional palacio que albergara lo mejor de la cultura decimonónica chilena hubiese pasado a convertirse en un lugar de tortura y muerte, también encuentra difícil conciliar la imagen de la joven estudiante Mónica, lectora de Joyce y Conrad, con aquella de una colaboradora de los militares. Los intentos de entender, de reconstruir, de fundar un sentido a partir de rearmar la historia de un espacio fracasan. El palacio de la risa cierra con la resignación de Germán ante la imposibilidad de hacer coincidir el pasado con el presente, así como de reconciliarse con el Chile que ha encontrado tras su vuelta del exilio:

Abrigar alguna esperanza de restituir la existencia a la antigua casa era quimérico, asimismo devolver a Mónica su vida anterior, a quien resultaba mejor olvidar $[\ldots]$

[...] el exilio todavía se prolongaba, transformado en cierta medida en un hombre invisible al que no reconocían ni siquiera sus ex compañeros de juego, a solas en medio de un pasado que ya no interesaba a nadie. Era un extranjero en mi propio país. Desde la orilla opuesta de este destierro, vivido durante diecisiete años, proseguía al volver con una historia escindida que no encajaba con el presente (100).

El palacio de la risa se configura en tanto historia de un fracaso: el personaje-narrador, focalizado en la reconstrucción de la historia de Villa Grimaldi, intenta una narración que lo haga entender tanto la historia de Chile como la suya propia. Historia colectiva e historia personal se entretejen de manera abigarrada, en ambas coincidiendo la falta de sentido y la incapacidad de llegar a una comprensión de los sucesos. El destierro de un espacio que se hace irreconocible funciona como simbolización del destierro de una unidad que cobije al individuo en estructuras que lo trasciendan. Las relaciones intersubjetivas son vinculaciones construidas en un espacio: el círculo de intimidad es una figura espacial. Es así como en la novela de Marín la historia de Mónica -historia que comenzó siendo de amor y terminó evidenciándose de terror- es metonimia de la historia del espacio de Villa Grimaldi. El espacio no hace posible la unidad; el individuo queda expulsado y retraído indefectiblemente a su propia desolación. Germán Marín reitera en su novela la historia mítica del ser humano, que Sloterdijk resume en la fórmula de unidad originaria, catástrofe de separación, intento de reconsti- 
tución. El palacio de la risa muestra precisamente la imposibilidad de aquella restitución de la unidad perdida.

\section{APOCALIPSIS Y MONSTRUOSIDAD EN ÍDOLA}

Tras despertar en el cuarto de un hotel con una considerable resaca, Germán se enfrenta en la novela Ídola, segunda de la trilogía Un animal mudo levanta la vista, a una escena apocalíptica de un Santiago en ruinas, producto de un terremoto que escenifica una pesadilla nocturna del personaje. La destrucción física de Santiago conlleva consigo la disolución de las normas sociales que organizan el cuerpo civil. El "Preludio", comienzo de la novela, está en su totalidad dedicado a la descripción de esta disolución del espacio físico y social, en la que la destrucción de edificios, calles y plazas tiene su reflejo en el derrumbe de toda cohesión social. Este comienzo se vincula con el "Finale" de la obra, en el que se retoma esta desestructuración espacial, social y moral evidenciada en el Preludio. ¿Qué sucede en los capítulos que conforma el cuerpo textual, enmarcados por Preludio y Finale, que justifique estas imágenes apocalípticas?

Piernas entreabiertas, un pubis de pelo negro, un vientre y un pecho de rosado pezón asomado bajo blancas sábanas: éste es el verdadero comienzo de Ídola. Antes de enfrentarse a texto escrito, el lector se convierte en un observador del cuadro L'origine du monde de Gustave Courbet (1866) . Un cuadro escándalo que ostenta un sexo femenino en primer plano, un fragmento de cuerpo que deja fuera lo que en nuestra cultura configura la identidad de un ser humano: el rostro. En la novela de Marín este cuadro tendrá un rol protagónico, obsesionándose Germán con la imagen del sexo femenino, tratando de indagar en el inescrutable secreto que éste encierra para él. El retrato llega a tener un correlato en Sofía, cuya boca roja y húmeda evoca en el narrador los labios vaginales del sexo de la modelo retratada en L'origine du monde. Germán sellará esta transposición de la obsesión con el cuadro volcada ahora a Sofía, comiéndose la postal con L'origine $d u$ monde: "Era la hostia sagrada con el recuerdo de la modelo irlandesa [...] desnudada por Courbet, que deseaba disolver en mí como una pócima para llegar en cuerpo y alma al templo del sexo de Sofía" (185). El acto simbólicamente antropofágico de Germán implica un intento de hacerse uno con

\footnotetext{
${ }^{4}$ En la edición de Un animal mudo levanta la vista se suprime la inclusión de la lámina que reproduce el cuadro de Courbet. Este análisis se basa -para tales efectos- en la edición de Ídola del año 2000 por Editorial Sudamericana.
} 
lo engullido. La comparación con el acto sagrado de ingerir la hostia -ritual que simboliza la actualización de la muerte de Cristo, haciéndose uno con su cuerpo- indica la apuesta del personaje por fusionarse con lo que come y trascender de este modo su individualidad.

En el primer encuentro sexual entre ambos, Sofía penetra con su clítoris a Germán, invirtiendo los roles sexuales tradicionalmente establecidos entre hombre y mujer:

Advertí de ese modo que una menuda serpiente eléctrica brotaba de las entrañas de Sofía y recordé, necesitado ante la duda de lo que sucedía, el motivo de la pintura de Gustave Courbet [...] La modelo irlandesa Jo tenía en la parte superior de la curva, gracias a la técnica lograda con el pincel romo, un punto escarlata casi incandescente que, en la realidad de esta noche, constituía en la pálida Sofía el aguijón encapuchado que, del largo aproximado de un dedo meñique, deseaba penetrar en mí (195).

Para Germán la inversión del acto de la penetración funciona como principio integrador, a partir del cual los contrarios se cautivan y fusionan en una nueva unidad. Los polos supuestamente contrarios evidencian ser, en realidad, elementos complementarios, que en un especial magnetismo se atraen y se muestran como dos caras de una misma moneda. Germán creerá haber encontrado su origen del mundo: no es, evidentemente, casual el nombre de Sofía, promesa de la contención del saber que Germán anhela encontrar entre sus piernas.

En el trabajo como guionistas de películas pornográficas clandestinas que Raúl Ruiz -quien no salió de Chile durante la dictadura militar ni tampoco logró hacer carrera cinematográfica ${ }^{5}$ le consigue, Germán asiste durante el día a largas y brutales sesiones de filmaciones porno, acostumbrándose a la violencia de las escenas que David Calisto, protagonista masculino de las cintas, encabeza:

En algunas sesiones $[\ldots]$ trataba al igual que un topo de meter la cabeza en el interior de la vagina, a semejanza ésta de una bolsa, observando quienes en torno seguíamos profesionalmente la apoteosis de la escena, cómo

\footnotetext{
${ }^{5}$ Esta inclusión del personaje de Raúl Ruiz es un ejemplo paradigmático para el juego con la verosimilitud que Germán Marín constituye en muchas de sus obras. Introduce un personaje conocido con su nombre "real", pero le cambia las coordenadas vitales que lo convierten precisamente en el personaje (re)conocido. El gesto irónico implicado hace innecesaria e inefectiva la pregunta respecto de la verosimilitud.
} 
luchaba por hacerlo [...] bajo el delirante propósito creo de desaparecer entre los muslos, en un regreso a la oscuridad de las vísceras (138).

La intimidad, incluyendo la erótica-sexual, en muchas aproximaciones culturales de Occidente ha sido entendida como un intento de reconectarse con la memoria de una unidad dual perdida. En un sentido platónico -así lo muestra Sloterdijk en Burbujas- la atracción entre dos cuerpos es una reiteración de una imagen originaria de fusión con lo divino: la cercanía en el ahora pone en escena un tiempo soterrado repitiendo una intimidad de antaño. En la perspectiva psicoanalítica, la intimidad busca la reminiscencia de la unidad pre-histórica de madre-hijo. La sexualidad, entonces, sería una búsqueda de ir en pos de este estado primigenio, microesferológico, bipolar.

L'origine du monde nos sitúa desde los comienzos del texto literario en la imagen de la vulva como portal hacia los orígenes perdidos. La obsesión del narrador con el cuadro responde a su terca fascinación con la posibilidad de re-encontrar esta dualidad disipada. En tanto origen perdido, es tan imposible su recuperación como ineludible su perpetua búsqueda. Como escribe Sloterdijk: "Alle Wahrheitssucher in metaphysischer Zeit sind darum ihrem Motiv nach Schoßheimkehrer. Sie streben an, was prima facie unerreichbar scheint - sie wollen das Ende der Suche an den Lebensanfang knüpfen und durch radikale Kämpfe gegen sich selbst die Geburt umkehren” $(280)^{6}$.

La imagen de Calisto entre los muslos de una mujer responde a la descripción de una búsqueda del origen degradada por la pornografía. Sloterdijk describe en su aproximación al tópico de la vulva como entrada a la búsqueda de la verdad la doble fascinación que ésta produce:

Sobald das weibliche Geburtsorgan nicht mehr nur den Ausgang bedeutet, den realen wie den imaginären, sondern auch zu einem Eingang geworden ist, durch den die Suche nach Identität hindurch muß, lädt es sich mit ambivalenten Faszinationen auf. Das blutende Tor zum Leben, dessen Klaffendes fasziniert, empört und abstößt, wird nun ein Zugang zur Unter- und Überwelt. Der Uterus wächst zum Jenseits heran, die Vulva wird zum grauenerregend-einladenden Portal dorthin" $(279)^{7}$.

\footnotetext{
6 "Por eso, en la era metafísica todos los buscadores de la verdad son, por su propio tema, gentes que regresan al seno materno. Aspiran a lo que prima facie parece inalcanzable: quieren enlazar el final de la búsqueda con el comienzo de la vida y dar la vuelta al nacimiento mediante peleas radicales consigo mismos" (256-257).

7 "Tan pronto como el órgano femenino del nacimiento ya no significa sólo la salida, la real como la imaginaria, sino que también se ha convertido en una entrada por la que debe penetrar la búsqueda de identidad, se carga de fascinaciones ambivalentes. La puerta sangrante a la vida,
} 
En Germán y Calisto se configuran estas dos opciones frente al sexo femenino: la venerante seducción, por un lado, y la horripilante fascinación que lleva a violar y destruir, por el otro.

El trabajo como dramaturgo pornográfico entra, en el imaginario de Germán, en conflicto con su obsesión traspasada del cuadro de Courbet al cuerpo de Sofía y la erótica inversión vivida con ella, que ha reinstaurado para la pareja la constitución de la sexualidad como un vínculo mágico, capaz de referir a la burbuja diádica originaria perdida. La confrontación cotidiana con esta hiperrealidad ${ }^{8}$ constituida a partir de las filmaciones, sin embargo, anuncia el desastre final de la trama novelesca. Germán terminará por violar el secreto que lo une a Sofía, violándola a ella. En el Finale de la novela, un Germán minusválido - producto de un accidente del que fuera intencionadamente víctima para acallarlo como potencial testigo de la red ilegal de pornografía- empuja un coche de guagua por las calles de un derrumbado barrio Brasil en Santiago Centro. El coche oculta a Asmodeo, el hijo monstruo que naciera tras la noche en que Germán penetrara contra su voluntad a Sofía. El nombre Asmodeo remite a un demonio del Antiguo Testamento, que en la Edad Media fuera asociado a uno de los siete pecados capitales: el de la lujuria.

En el Finale confluyen todos los momentos apocalípticos de la novela: la ruptura de la burbuja diádica que construyeron Germán y Sofía queda simbólicamente representada en el hijo monstruo, en la minusvalía del narrador y en un Santiago destruido que, en el final de la novela, vuelve a aparecer como escenario resultante de la trama novelesca que nos relata la violación de un secreto que prometía encontrar el origen del mundo a partir del regreso a su conformación esférica originaria. Las burbujas, siguiendo a Sloterdijk, que Germán ha intentado construir para protegerse frente a las amenazas del exterior -desarraigo, soledad, sinsentido- se han destruido. La intimidad con Sofía, en su inicio esfera protectora, termina por ser violada

cuya hendidura fascina, indigna y repele, se convierte ahora en acceso al infra y al supramundo. El útero va creciendo hasta el más allá, la vulva se convierte en un portal hacia él, horrible a la vez que atractivo" (254-255).

${ }^{8}$ Baudrillard reflexiona acerca de la pornografía a partir de la consideración de la hiperrealidad buscada y constituida por el porno con relación a la sexualidad: "Inútil buscar qué fantasmas obsesionan a la pornografía [...] pues están eliminados por el exceso de >realidad <" (2007: 33). La pornografía vuelve visible lo que no suele serlo, abre perspectivas y posibilita close-ups que posicionan los órganos sexuales, las aperturas, los recovecos en la luminosidad de lo visible, evidenciable, sonsacándole así a la erótica lo que de secreto y promesa contiene. La cercanía creada frente al objeto captado por el camarógrafo porno lo vuelve más que real. Baudrillard escribe: "El único fantasma en juego en el porno, si es que hay uno, no es el del sexo, sino el de lo real, y su absorción, absorción en otra cosa distinta de lo real, en lo hiperreal" (33). 
por el propio Germán, dejando símbolos unívocos de su destrucción. El personaje es arrojado hacia su condición solitaria, física y psíquicamente vulnerado, abandonado a la precariedad de su existencia. Ídola se lee, desde la perspectiva propuesta, en tanto narración del fracaso de un espacio de intimidad, en el cual la subjetividad sólo alcanza su plenitud en cuanto es compartida. La novela Ídola nos relata la constitución de un espacio íntimo esferológico y su posterior destrucción, con la desolación resultante de esta pérdida catastrófica.

\section{FINAL DE JUEGO EN CARTAGO}

Cartago inicia su trama después de terminada la relación con Sofía, viviendo Germán solo y retirado. Una vez más de paseo por los parajes en los que antaño se encontraba el Palacio de Peñalolén, Germán encuentra un brazo de mujer, fragmento de un cuerpo que remite simultáneamente a los horrores dictatoriales que sucedieron en el palacio de la risa, como a las posibilidades desvanecidas de amor - de fusión con otro para conformar una dualidad trascendente de la individualidad- encarnadas en las figuras de Mónica y luego de Sofía. Resignado a una vida pasiva, concentrada en el trabajo insatisfactorio en una editorial y en la relación erótica-amorosa con "El Brazo", Germán vuelve a encontrarse con un ex compañero de su pasada por la Escuela Militar. Mientras que Germán se vio obligado a abandonar Chile, Aburto ha hecho carrera como militar. En noches regadas de alcohol, ambos se entregan a los recuerdos que guardan de su época de juventud: "El pasado [...] tendía a ser entre nosotros el eslabón perdido, el punto de encuentro de esas charlas" (411). Pronto la animosidad se instala entre ambos, venciendo las desavenencias políticas por sobre los momentos compartidos. Entrampados en una especie de obsesión mutua, se reúnen en las noches y beben hasta altas horas de la noche, insultándose y dando rienda suelta a sus agresiones. Creen encontrar en el "Caro", un juego de azar de dados, la manera de canalizar sus desacuerdos y deciden "[...] apostar cada uno algo así como ideas queridas que, de perder, sólo dolieran en el alma, dispuestos a ese riesgo que, en apariencia, veíamos de un menor costo" (444). Apuestan una canción de Violeta Parra contra una de los Huasos Quincheros, una imagen del Che Guevara contra otra del general Contreras, "La Internacional" contra la "marcha Radetzky" y el recuerdo de Pablo Neruda contra la figura de Carlos Ibáñez del Campo. El precario equilibrio que aparentemente alcanzan con los vaivenes del azar para uno y el otro lado se devela como ilusorio: 
Sobre nosotros flotaba como un viejo y negro paño bañado de sangre el recuerdo del 11 de septiembre de 1973, fecha remota en apariencia, que, mediante los subterfugios, habíamos tratado de soslayar en los primeros encuentros. Anidábamos en el interior de cada cual unos pensamientos irreconciliables, no obstante respirar bajo el mismo venenoso aire, de convivir bajo las mismas leyes [...] (451).

El juego lleva inevitablemente a que en una fría madrugada apuesten el recuerdo de Allende contra el de Pinochet. Tras perder Germán, le da un golpe fatal a Aburto, desenlace que explica su estancia en la institución psiquiátrica, punto cero desde el cual mira y relata los sucesos que conforman el cuerpo novelesco, incapaz de darles algún sentido. La relación que Germán establece con Aburto es paradigmática para la interpretación que Marín propone en su trilogía sobre la historia de Chile: el golpe militar y la dictadura son los hechos que marcan el destino tanto individual como colectivo de los chilenos. Tratándose de un pasado no superable, pero tampoco interpretable de manera satisfactoria desde un presente, éste se instala como ineludible sinsentido en la historia de Chile. Será un juego de azar el que decida sobre la exégesis posible de esa historia. Irremediablemente expulsados de un espacio unitario, colmado de sentido, cayendo de este modo también fuera del tiempo, la historia individual de Germán refleja en un doloroso gesto la historia de Chile. Nos encontramos en Cartago frente a un espacio tanto físico como social derruido, en cuyas ruinas Germán revolotea, en un último infructuoso gesto de fundar algún sentido para su existencia y para la historia de Chile.

La trama de Cartago está caracterizada desde su comienzo por lo pesadillesco. Ceterum censeo Carthaginem esse delendam, predicaba Cato el Viejo, senador romano, para enfrentarse al poder de Cartago y la necesidad de destruirla. Tras largos y pérfidos años de guerra de Roma contra Cartago, ésta termina siendo completamente destruida. En el siglo XIX se expande la leyenda de que, tras su derrota, Cartago habría sido sembrada con sal para volverla definitivamente infértil. El imaginario histórico representa a Cartago como símbolo de destrucción y muerte, imágenes que Marín evoca en el título de la tercera parte de la trilogía. Como en Cartago, sólo reina la destrucción; como en la octava Elegía de Rilke, el destino es mudo, insoslayable e incomprensible a la vez. Tras la atmósfera apocalíptica que enmarca Ídola, que termina confluyendo en la figura del hijo-monstruo Asmodeo, en Cartago nos encontramos ante la Post-Apocalipsis. Mientras que en El palacio de la risa, el personaje intenta reconstruir su historia, enmarañada con la 
historia colectiva de Chile, en Cartago cualquier intento de reconstrucción se devela como inútil desde sus comienzos. Si en Ídola el amor, asociado a la búsqueda de un origen, de una genealogía, de un sentido, aún parecía posible, en Cartago la única relación amorosa que se erige como viable se establece con un pedazo de cuerpo, símbolo de la fragmentación tanto de la historia del personaje como la de Chile.

Sloterdijk plantea en la parte final de Burbujas que la vida sólo es posible en tanto inmersa en la vida, es decir vinculada y unida a otras vidas, proponiendo el espacio relacional como una esfera protectora: "In-Sein ist also zu denken als das Zusammensein von Etwas mit Etwas in Etwas" (552) ${ }^{9}$. El alto grado de abstracción que mantiene este "algo" que cohabita con otro "algo" es lo que permite a Sloterdijk pensar relatos culturales tan diversos como la relación del alma con Dios en la tradición cristiana, la vinculación de "Urbild" y "Abbild" en el pensamiento platónico, los paralelismos establecidos entre bebé y placenta en muchas culturas primitivas, o la díada psicoanalítica de madre-hijo. En todos estos modelos se daría cuenta de que la subjetividad no es cuestión del individuo aislado, sino de un despliegue que tiene lugar en una figura espacial con un "otro", que pierde su carácter de Otredad por sólo existir como complemento necesario del "uno" que, de este modo, es siempre al menos "dos". Sin embargo, es el quiebre de esta unidad primaria la que recién visibiliza lo perdido. Unidad y ruptura se condicionan mutuamente y se conforman en tanto catástrofe humana: "Aber weil der Bruch die Beziehung als solche erst ermöglicht und erkennbar macht, so kann, wie es scheint, die Wahrheit über das Gesamtverhältnis nur nachträglich vor Augen kommen - und wie man verschärfend sagen könnte: von vornherein nachträglich" $(558)^{10}$.

La tercera de las novelas que conforman Un animal mudo que levanta la vista arranca desde esta posterioridad señalada por Sloterdijk, evidenciando el anhelo a la unidad perdida como fútil e irremediablemente pasado.

\section{A MODO DE CONCLUSIÓN}

Establecer un diálogo entre la obra filosófica Burbujas de Sloterdijk y la trilogía Un animal mudo que levanta la vista permite develar aspectos de la

\footnotetext{
9 "El ser-en hay que entenderlo, pues, como la convivencia de algo con algo en algo" (487).

10 "Pero la verdad sobre la relación completa sólo puede aparecer ante los ojos porque la ruptura posibilita y hace reconocible primero la relación como tal; y sólo puede aparecer posteriormente, o como podría decirse agudizándolo: posterior-inicialmente" (491-492).
} 
narrativa de Marín que trascienden el marco interpretativo que ha dominado en las aproximaciones a la novelística del autor chileno. Los quiebres de los cuales Marín da cuenta en las tres novelas revisadas evidencian una proveniencia que no sólo remite a la historia dictatorial chilena y la imposibilidad de una reconciliación con ella, sino a su vez, esta historia sirve como simbolización de una pérdida existencial. Tomando como modelo para esta disipación de una unidad originaria la propuesta filosófica de la burbuja diádica de Sloterdijk, se ha mostrado cómo en las novelas de Marín se vislumbra una posibilidad de reconexión con una unidad perdida que luego se devela en tanto ilusoria. La historia chilena puede ser entendida como parte de un todo roto, una catástrofe que entra en relación metonímica con la catástrofe existencial moderna del ser humano. Desde esta lectura, la trilogía de Marín se aboca -insinuándose esta crítica desde el intertexto con Rilke-a una revisión de los preceptos de la modernidad, cuestionando la celebración que en ella se hace de la individualidad del sujeto. Como Sloterdijk, Marín pareciera echar en falta una individualidad que llega a su despliegue feliz sólo en conjunción con un "otro". En la trilogía, este "otro" adquiere distintas posibilidades de actualización: la reconstitución de un espacio armónico recreado desde la infancia, las relaciones amorosas con Mónica y Sofía, la relación sexual invertida con Sofía, la idea de la vulva como origen, o la autoría interpretativa sobre la historia reciente. La novelística de Germán Marín mostrará como imposible esta reconstitución, pero la nostalgia por la pérdida y la incesante necesidad de mitigarla marcan la totalidad de los textos que conforman Un animal mudo que levanta la vista.

\section{REFERENCIAS}

Barreto, Iván. 2006. "La pérdida del origen en el neoliberalismo", en Crítica.cl. (En línea) Disponible en: http://www.critica.cl/html/barreto_moroni_01.htm. Consulta: 12/09/2010.

Baudrillard, Jean. 2007. De la seducción. Trad. de Elena Benarroch. Madrid: Ediciones Cátedra, 175 pp.

Costabal, Soledad. 2008. "La narración como proyección del olvido en $E l$ palacio de la risa de Germán Marín”. (En línea) Disponible en: http:// www.cybertesis.cl/tesis/uchile/2008/costabal_s/html/index-frames. html. Consulta: 12/09/2010.

Cuevas, José Ángel. 2001. "Los quebranta sesos”, en La calabaza del diablo 2. 
Espinosa, Patricia. 2000. "El racismo de la inteligencia”, en Rocinante 23. Marín, Germán. 1995. El palacio de la risa. Santiago de Chile: Planeta, 134 pp. 2000. Ídola. Santiago de Chile: Editorial Sudamericana, 224 pp. 2001. Cartago. Santiago de Chile: Editorial Sudamericana, 152 pp. 2002. Un animal mudo levanta la vista. Santiago de Chile: Editorial Sudamericana, $455 \mathrm{pp}$.

Rilke, Rainer Maria. 1946. Duisener Elegien. Wiesbaden: Insel Verlag, 40 pp. 1992. Requiem. Elegias de Duino. Trad. de Mechthild von Hese Podewils y Gonzalo Torrente Ballester. Madrid: Jucar, 220 pp.

Sloterdijk, Peter. 1998. Sphären I (Blasen). Frankfurt am Main: Suhrkamp, $644 \mathrm{pp}$.

2003. Esferas I (Burbujas). Trad. de Isidoro Reguera. Madrid: Ediciones Siruela, 583 pp. 